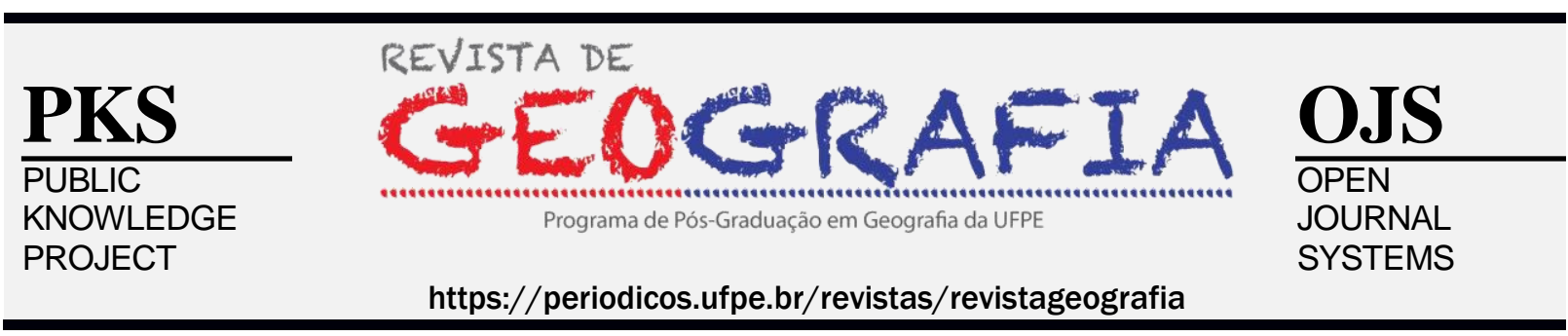

\title{
SUSCEPTIBILIDADE EROSIVA DA PAISAGEM DA SERRA DO TEPEQUÉM - RORAIMA - BRASIL
}

\author{
Elizabete do Nascimento Cavalcante ${ }^{1}$, Luiza Câmara Beserra Neta ${ }^{2}$, Stélio Soares \\ Tavares Júnior $^{3}$
}

\begin{abstract}
${ }^{1}$ Doutoranda do Programa de Pós-graduação em Geografia-UNIR. E-mail: elizzal @hotmail.com
${ }^{2}$ Professora associada da Universidade Federal de Roraima. E-mail: luiza.camara@ufrr.br

${ }^{3}$ Professor associado IV da Universidade Federal de Roraima. E-mail: stelio.tavares@ufrr.br
\end{abstract}

Artigo recebido em 11/10/2018 e aceito em 08/05/2019

DOI:

\begin{abstract}
RESUMO
A serra do Tepequém, área foco do estudo, localiza-se no estado de Roraima no município do Amajarí. Destacase na paisagem por apresentar variações altimétricas formando um conjunto de morros alinhados, colinas e escarpas abruptas. Geologicamente, corresponde a um testemunho isolado formado em rochas sedimentares de idade Paleoproterozóica, composta por arenitos, arenitos conglomeráticos, siltitos e argilitos, pertencentes à Formação Tepequém. Os solos são arenosos recobertos parcialmente por savana arbustiva rasteira. O clima é quente e úmido (Am) com temperaturas médias em torno de 22 graus, com elevado índice pluviométrico em média de $2.250 \mathrm{~mm}$ anuais. A declividade da área é representada por valores que variam de $>0,1^{\circ} \mathrm{a}<4^{\circ}$. A combinação dos elementos fisiográficos auxiliam na evolução da paisagem, podendo ser evidenciada no surgimento e evolução de feições erosivas lineares. Objetivou-se através desse estudo identificar as feições erosivas, bem como, seus condicionantes.
\end{abstract}

Palavras-chave: . Paisagem; Voçorocas; Degradação.

\section{EROSIVE SUSCEPTIBILITY OF THE TEPEQUÉM SAW LANDSCAPE - RORAIMA - BRAZIL}

\section{ABSTRACT}

The Tepequém mountain range, the study's focus area, is located in the state of Roraima in the municipality of Amajarí. It stands out in the landscape for presenting altimetric variations forming a set of aligned hills, hills and abrupt escarpments. Geologically, it corresponds to an isolated testimony formed in sedimentary rocks of Paleoproterozoic age, composed of sandstones, conglomeratic sandstones, siltstones and mudstones belonging to the Training Tepequém. Soils are sandy partially covered by bushy bush savanna. The weather is hot and humid (Am) with temperatures around 22 degrees, with high rainfall average annual $2.250 \mathrm{~mm}$. The slope of the area is represented by values ranging from $>0.1^{\circ}$ to $<4^{\circ}$. The combination of the physiographic elements helps in the evolution of the landscape, and can be evidenced in the emergence and evolution of linear erosive features. The objective of this study was to identify erosive features, as well as their conditioning factors.

Keywords: Landscape; Gully; Degradation. 


\section{INTRODUÇÃO}

A área do estudo localiza-se no município Amajarí, no estado Roraima, denominada serra do Tepequém, apresenta coordenadas $3^{\circ} 42^{\prime}$ e $3^{\circ} 50^{\prime} \mathrm{N}$ e $61^{\circ} 40^{\prime}$ e $61^{\circ} 48^{\prime} \mathrm{W}$ (Figura 1). Com variações altimétricas de 650 a $1100 \mathrm{~m}$ destaca-se por suas características peculiares com planícies entre morros alinhados, escarpas abruptas formando uma diversidade de paisagens.

Figura 1 - Localização da serra do Tepequém no Estado de Roraima.

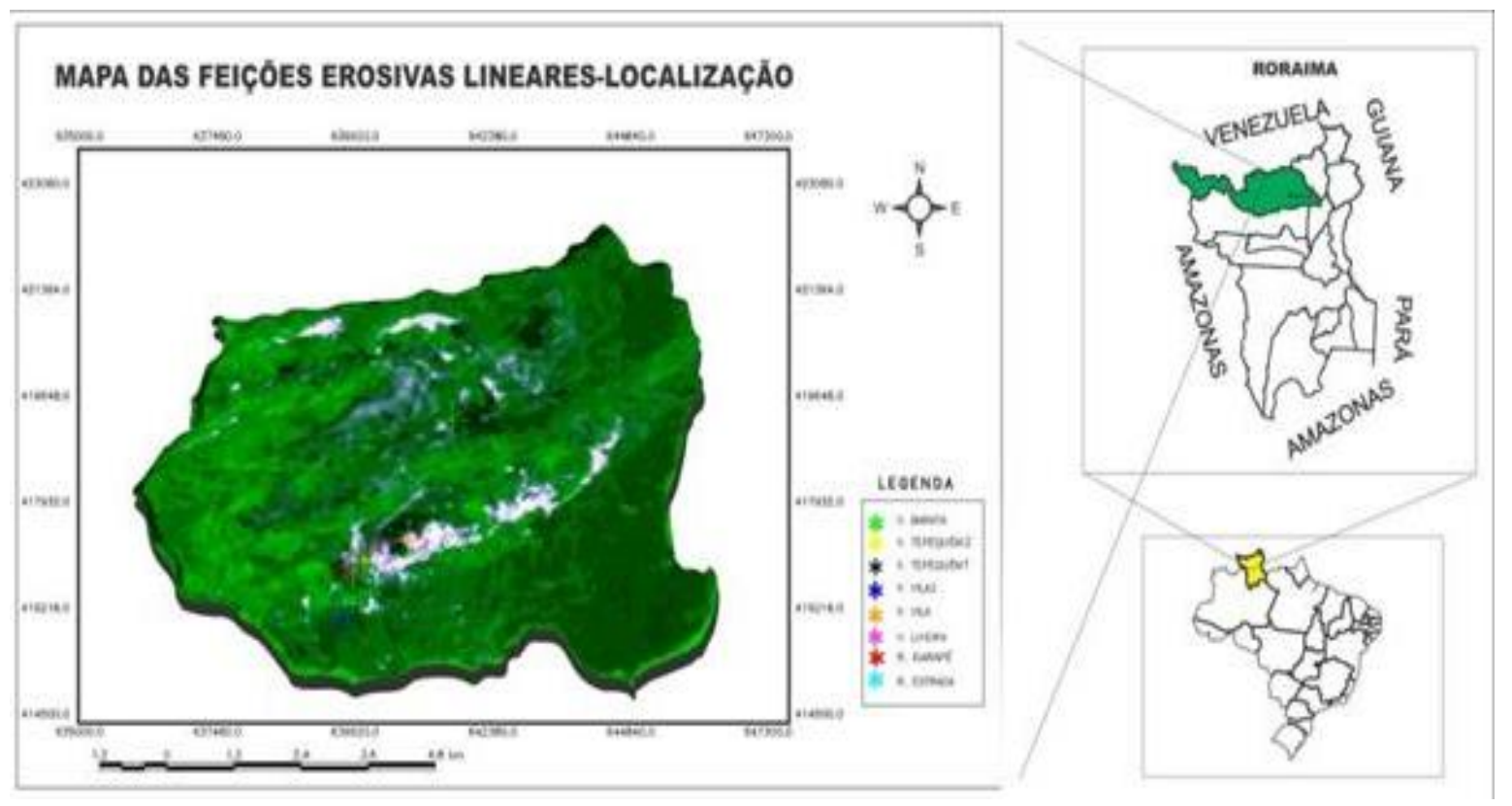

As erosões lineares no topo da serra do Tepequém tornaram-se palco de análises e estudos (BESERRA NETA, COSTA, BORGES, 2007; BESERRA NETA, 2008) visto que estas são visíveis e frequentes nas planícies intermontanas. A pesquisa em questão retrata acerca das feições erosivas lineares da serra do Tepequém, bem como seus condicionantes, tendo como base dados morfométricos das calhas das mesmas.

Para melhor compreensão destes processos erosivos lineares, é necessário citar que eles sofrem influência de vários fatores (CARVALHO, et al., 2009; MOURA e SIMÕES, 2010), entre eles se destacam a declividade (GUERRA, 2010), tipo de cobertura vegetal (VIEIRA et al., 2012), precipitação (BIGARELLA et al., 2007), litologia e solos. As feições erosivas lineares, ravinas e voçorocas são causadas por vários mecanismos que agem em diferentes escalas temporais e espaciais. No entanto, todos derivam de rotas preferenciais adotadas pelos fluxos das águas, esse processo pode ocorrer tanto na superfície e/ou em subsuperfície (COELHO NETTO, 1995). 
Além disso, as ravinas podem evoluir para voçorocas, se considerado a interpretação de Guerra, em especial quando não são obliteradas pelas práticas agrícolas ou quando chuvas concentradas caem sobre encostas com ravinas, sem proteção vegetal e que estejam sob superpastoreio.

$\mathrm{O}$ alargamento e aprofundamento das ravinas podem dar origem a voçorocas, devido à ação erosiva das águas na base e nas partes laterais das ravinas (GUERRA, 1995; GUERRA; BOTELHO, 1996).

Dentre outros fatores, a textura e a profundidade do solo, tem influência na maior ou menor quantidade de terra arrastada pelo escoamento superficial. Um solo arenoso com espaços porosos grandes, durante chuvas de baixa e de média intensidade pode absorver toda água, não havendo, portanto, grandes problemas relacionados com a erosão (COELHO NETTO, 1995).

As condições físicas em subsuperfície influenciam no surgimento de feições, dentre elas destacam-se aquelas que definem a qualidade da estrutura e do espaço poroso do solo. A estrutura do solo é mais bem distinguida por ajustes de características e propriedades físicas do solo, o que dificulta encontrar uma variável simples que a represente adequadamente em termos quantitativos (VOLK; COGO; STRECK, 2004).

Dentre outros fatores, a textura e a profundidade do solo, tem influência na maior ou menor quantidade de terra arrastada pelo escoamento superficial. Um solo arenoso com espaços porosos grandes, durante chuvas de baixa e de média intensidade, pode absorver toda água, não havendo, portanto, grandes problemas relacionados com a erosão (COELHO NETTO, 1995).

A paisagem da serra do Tepequém registra características históricas importantes, tornando possível observar intensas modificações advindas da atividade garimpeira diamantífera a partir da década de 1930. O garimpo atraiu imigrantes de vários estados brasileiros tendo seu auge no período entre 1941 e 1943 (GUERRA, 1957).

No auge da exploração diamantífera ocorreram intervenções antrópicas, como exemplo, abertura de cavas e o desvio de rios para extrair o diamante. A vegetação das margens dos rios Paiva e cabo Sobral também foram comprometidas.

Melo e Almeida Filho (1996) relatam que durante anos a atividade garimpeira foi a única desenvolvida por muitos moradores da região norte, na serra do Tepequém a situação não foi diferente, a atividade garimpeira diamantífera e de ouro contribuiu significativamente para degradação dos rios Paiva e Cabo Sobral, principalmente pelo uso de técnicas 
rudimentares, que desencadeiam a contaminação dos rios pelo mercúrio, desmatamentos das matas ciliares e assoreamento dos rios.

A paisagem local do Tepequém destaca-se por interromper a extensa de planura regional que a antecede e por sua morfologia (figura 2) que é constituída de escarpas íngremes de entorno e topo irregularmente aplainado, sendo estas condicionadas às estruturas geológicas. Tais características geram um cenário individualizado de planícies, vales, colinas e morros alinhados.

Figura 2 - Visão panorâmica da serra do Tepequém e da planície que a antecede.

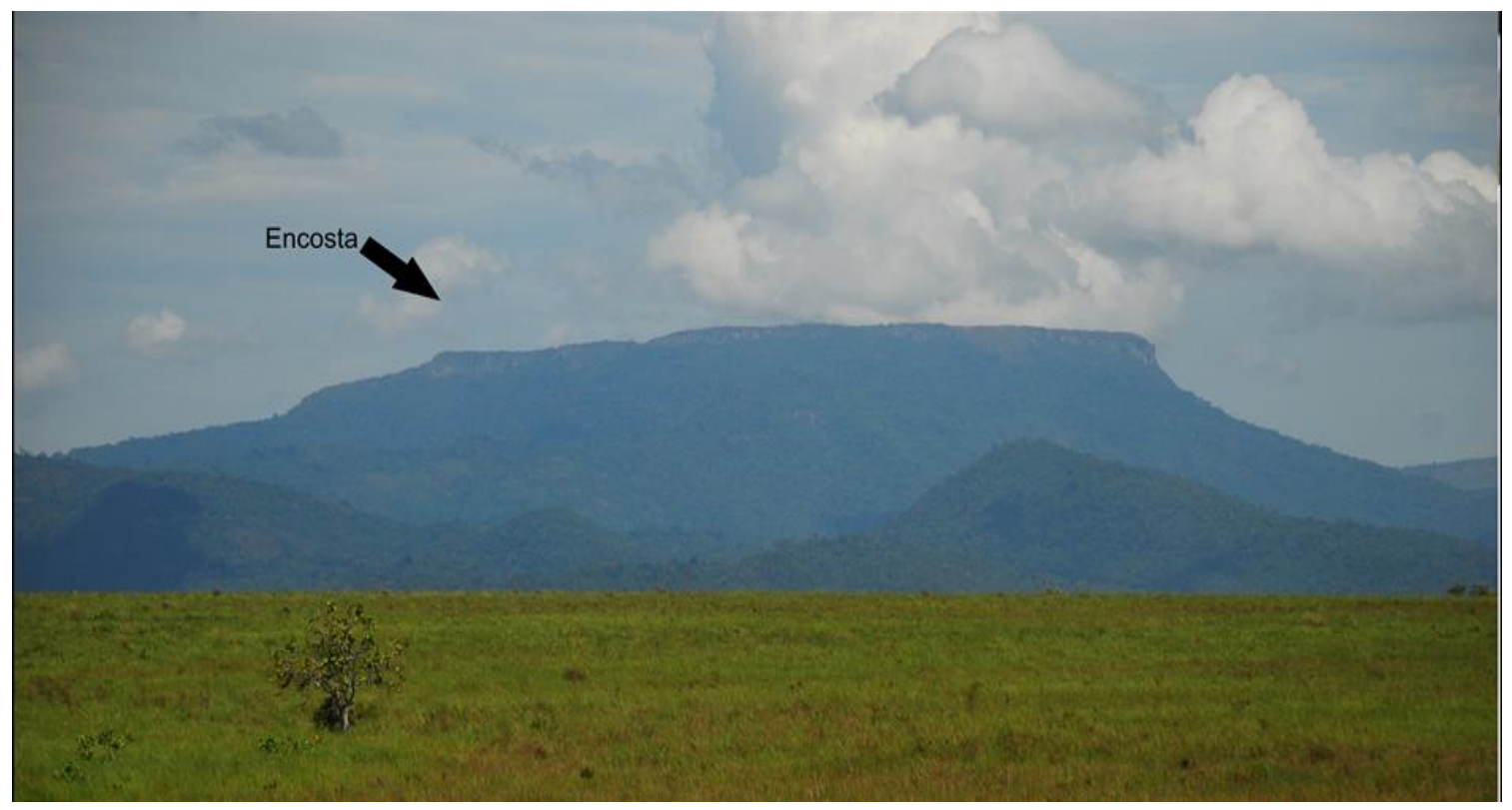

A paisagem da serra do Tepequém ao longo do tempo vem passando por contínuo retrabalhamento erosivo, influenciado por fatores como litologia, clima, relevo, vegetação, solos e etc., esses fatores tornam o solo mais friável e propenso à ação erosiva. No entanto, é indispensável reconhecer que a ação antrópica deu uma parcela de contribuição no aceleramento do processo erosivo, destacando-se a atividade garimpeira de diamante, desenvolvida nos aluviões e secundariamente nos elúvios, colúvios e conglomerados da formação Tepequém.

As feições erosivas, que compõem a paisagem atual da serra, têm ocorrência predominante nas áreas de planícies e secundariamente nas vertentes de morros e colinas. A fragilidade física deste ambiente associada às atividades antropogênicas constituem fatores condicionantes nos processos de surgimento e evolução dessas feições erosivas. 
Tardin (2010) colabora com o entendimento da vulnerabilidade da paisagem quando relata que um sistema é um conjunto de elementos passíveis de estabelecer inter-relações, físicas, funcionais e relativas à vivência da paisagem, abertas e intricadas entre si, com seu entorno e com as pessoas que o vivenciam, onde a organização física da paisagem sistêmica significa levar em consideração que a paisagem está viva e passa por mudanças, deve considerar que ela é composta por sistemas integrados e, também interligados e interrelacionados, cuja articulação é uma condição fundamental para que as partes possam desenvolver-se inteiramente.

\section{MATERIAIS E MÉTODOS}

O estudo sobre a ação erosiva linear na serra do Tepequém foi desenvolvido a partir de levantamento bibliográfico da temática, seguido de levantamento da base cartográfica da serra do Tepequém e de imagens de satélite. As imagens orbitais utilizadas no estudo foram retiradas do catalogo do CBERES, em 02/04/2007 com resolução de 20m.

Foram realizadas duas etapas de campo (outubro e dezembro/2012) que constaram de atividades como: descrição da paisagem, levantamento do tipo de vegetação predominante nas áreas com erosões; medições morfométricas das calhas de duas ravinas e seis voçorocas, considerando os aspectos das cabeceiras, extensão, largura, profundidade, inclinação dos taludes e bifurcações.

Os taludes das voçorocas foram analisados e descritos quanto à presença de dutos, que são áreas com pequenas cavidades, que podem ter sua origem a partir da ação biogênica e das águas subsuperficiais.

Para aquisição dos dados de declividade do terreno foi utilizado inclinômetro digital e para aquisição de fotografias foi utilizada máquina digital.

O levantamento das medidas das feições erosivas foi realizado com auxílio de uma trena manual no local. Em cada feição foram medidas o tamanho das de montante a jusante e os taludes. Para obtenção das coordenadas Geográficas, utilizou-se GPS tipo Garmim, Datum WGS-84, zona 20.

\section{RESULTADOS E DISCUSSÃO}

A serra do Tepequém apresenta feições erosivas que se distinguem em ravinas e voçorocas. Segundo Guerra e Guerra (2010) a definição de ravinas e voçorocas segue um critério métrico, uma vez que ravinas são incisões lineares com profundidade e largura 
menores que 50 centímetros e voçorocas são incisões lineares com profundidade e largura maiores que 50 centímetros.

Vários são os critérios de identificação das feições erosivas lineares, por entender que essa conceptualização leva em conta um critério de melhor distinção e mensuração, esta pesquisa aderiu a conceptualização de Guerra para ravinas e voçorocas. As feições erosivas lineares estudadas na serra do Tepequém encontram-se concentradas nas planícies intermontanas, nas proximidades dos igarapés, por exemplo, o igarapé Paiva, situado na porção sul da serra.

$\mathrm{Na}$ área aonde se encontram as voçorocas, os solos são arenosos e predominantemente recobertos por savana arbustiva rasteira, que recobre parcialmente os solos vindos a favorecer ao processo de salpicamento, também denominado efeito splash, (erosão promovida pela chuva), que por consequência favorece o efeito de encrostamento do solo, uma vez que remove pequenas partículas de solos e deposita nos poros (vazios) dificultando a infiltração da água e consequentemente facilitando o escoamento das águas em superfície e em subsuperfície, resultando em caminhos preferenciais das águas e esses caminhos serão cavados continuamente até resultar em ravinas e voçorocas.

A declividade das áreas erosivas apresentou valores que variam de $>0,10^{\circ} \mathrm{e}<\mathrm{de} 4^{\circ}$. A declividade da encosta tem influência direta na erosão, por influenciar nas taxas de infiltração e na velocidade em que ocorre o escoamento superficial, ressaltando que em encostas muito íngremes há diminuição do material disponível para remoção, diminuindo a erosão (GUERRA, 2010). A topografia é um fator decisivo no escoamento das águas, pois elas tendem as percorre das áreas mais elevadas para as mais baixas durante os eventos chuvosos.

A partir de dados de campo foram observados as seguintes características morfológicas das voçorocas estudadas:

A voçoroca denominada vila1, apresenta processo de evolução avançado tendo atingido o lençol freático, a morfologia do canal tem a forma de $U$ e suas paredes são bem íngremes, o que resulta em deslocamento severo das águas, colaborando com a remoção e carregamento dos sedimentos. Na cabeceira, a erosão apresentou três (3) bifurcações, o que leva ao entendimento de que além da ação das águas superficiais, ocorre também ação das águas subsuperficiais.

A voçoroca vila 2, na porção jusante atingiu a rocha o que formou um canal estreito, pois a rocha tende a ser mais resistente a ação pluvial, a resistência litológica imprimiu menores dimensões de largura, resultando em canal estreito e em forma de U. 
A voçoroca Tepequém 1 tem seu canal em formato de U que se alarga em direção à jusante, fato que ocorre devido aos taludes não oferecem coesão suficiente, pois se encontram profundamente alterado pelo intemperismo químico. Outro fator que colabora nessa evolução lateral é a falta de vegetação, o que resulta em maior contato pluvial como solo e também colabora por não adicionar matéria orgânica ao solo, um importante material cimentante natural.

A voçoroca Tepequém 2 apresentou seis bifurcações, o que demonstra intensa atuação das águas em subsuperfície, assim como, a existência de áreas de abatimento. Fato esse constatado com identificação de áreas de abatimento no entorno. Essas aéreas de abatimento diante da dinâmica superficial e subsuperficial se unirão às voçorocas vindo a formar novas bifurcações, o que contribuirá ainda mais para a evolução da voçoroca.

$\mathrm{Na}$ voçoroca da Lixeira, o canal é raso e estreito, fundo em forma de U. Junto à jusante do seu canal foi observado acúmulo de lixo, que possivelmente venha de áreas mais a montante e que foram carregados durante eventos chuvosos.

A voçoroca do Barata apresenta canal em forma de V, o que denota resistência do material, que ao se deparar com a resistência litológica perde poder de remoção e vai agindo mais lentamente, no entanto, essa ação continuada vem promovendo o aprofundamento do canal, visto que a erosão já atingiu o lençol freático (Figura 3).

Figura 3: Destaca o canal em forma de $\mathrm{V}$ da voçoroca do barata, na figura $\mathrm{A}$, e na figura $\mathrm{B}, \mathrm{o}$ canal em forma de $\mathrm{U}$, da voçoroca da lixeira.

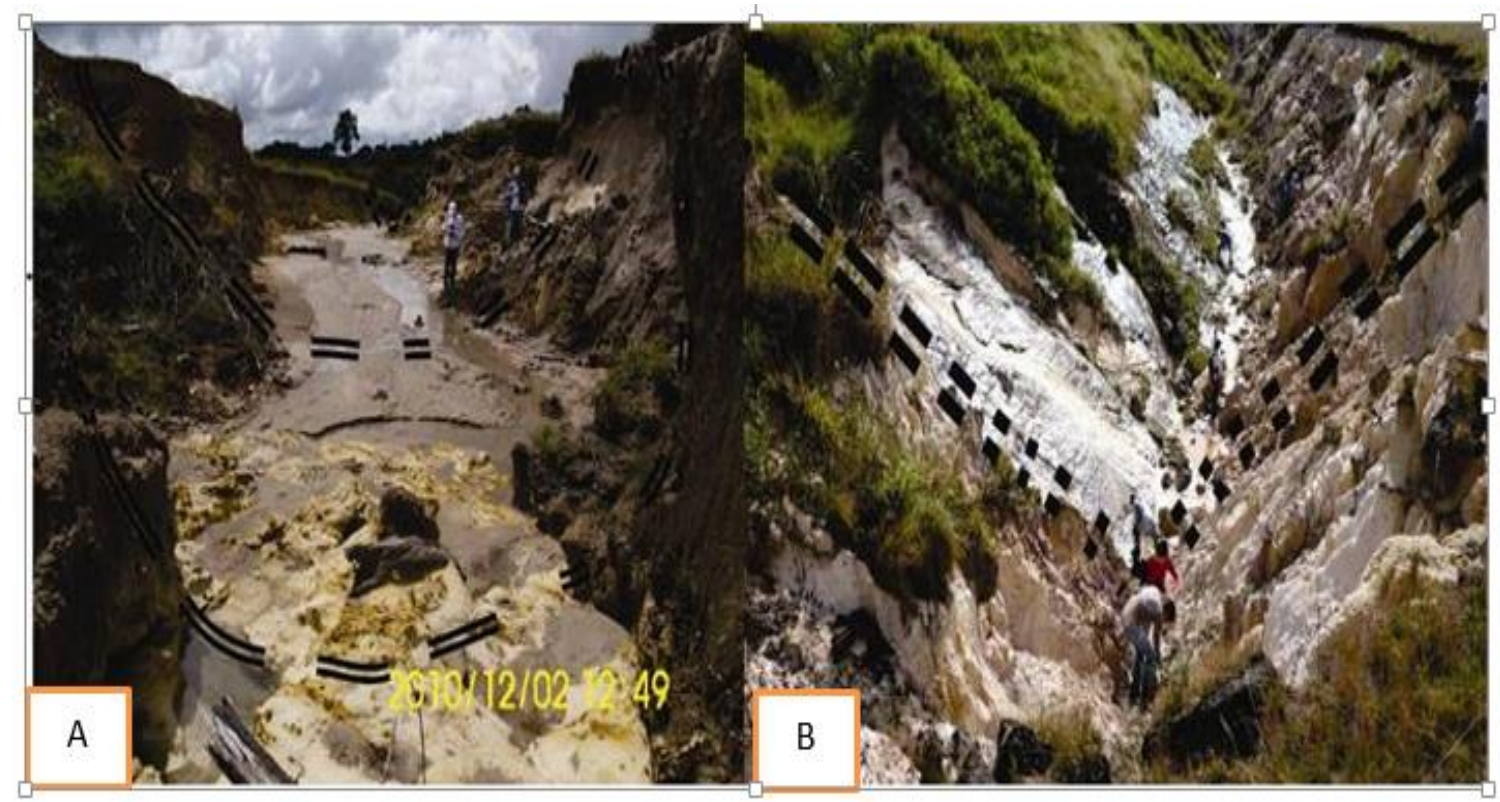


As medidas morfométricas das voçorocas quanto à largura variaram de 2,25m a $14,50 \mathrm{~m}$; e os comprimentos de montante a jusante de $6,08 \mathrm{~m}$ a $397 \mathrm{~m}$; a profundidade variou de $0,67 \mathrm{~m}$ a $12,30 \mathrm{~m}$. Nos taludes das feições erosivas foram observados dutos biogênicos (formigueiros) os quais apresentavam as seguintes dimensões: largura variando de 0,7 a 0,33 cm e comprimento de 0,7 a $0,36 \mathrm{~cm}$. Também foram observados erosões subsuperficiais na forma de áreas de abatimento, os quais apresentaram as seguintes dimensões: largura variando de $0,12 \mathrm{~cm}$ a $1,90 \mathrm{~m}$ e comprimento de $0,14 \mathrm{~cm}$ a $1,80 \mathrm{~m}$. Dutos preenchidos mostram a ação das águas em subsuperfície, assim como, seu poder de translocação de sedimentos (Figura 4).

Nas ravinas estudadas, observou-se desmoronamentos recentes nas paredes e no fundo acumulo de sedimentos, além de reentrâncias, demonstrando avanço no processo erosivo. Nessas feições o que se observou foi um possível início do processo erosivo e que se não solucionado, vai evoluir e resultar em voçoroca. Em todas as feições estudadas, o processo de remoção do solo é iniciado em áreas sem cobertura vegetal e com declividade variando de baixa a média.

Figura 4: Destaca a ação biogênica no talude da voçoroca da vila 2.

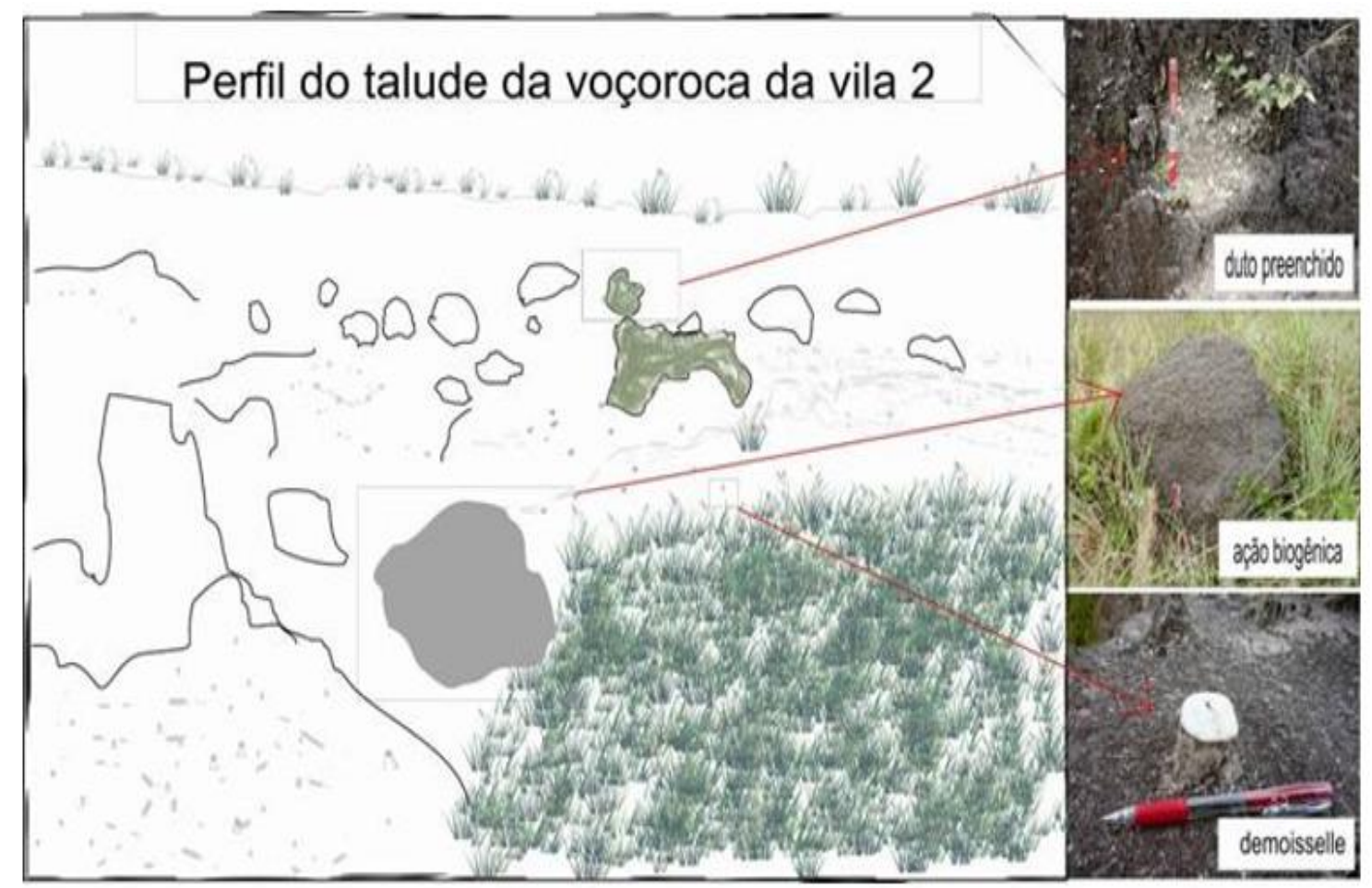

Os desmoronamentos identificados foram considerados como recentes e localizavamse situados nas paredes das feições erosivas. Os acúmulos notáveis dos sedimentos no fundo 
do canal demonstraram que as voçorocas estão em continuo processo de perdas de material, o que resulta em constante evolução.

Com a contínua perda de sedimentos as erosões lineares (voçorocas) chegaram a atingir o lençol freático, o que culminou em conexão com a rede de drenagem. As voçorocas conectadas a rede de drenagem atenderam a 75\%, e as desconectadas as redes de drenagem, a $25 \%$ (Figura 5).

Figura 5: Espacialização das voçorocas conectadas na Serra do Tepequém.

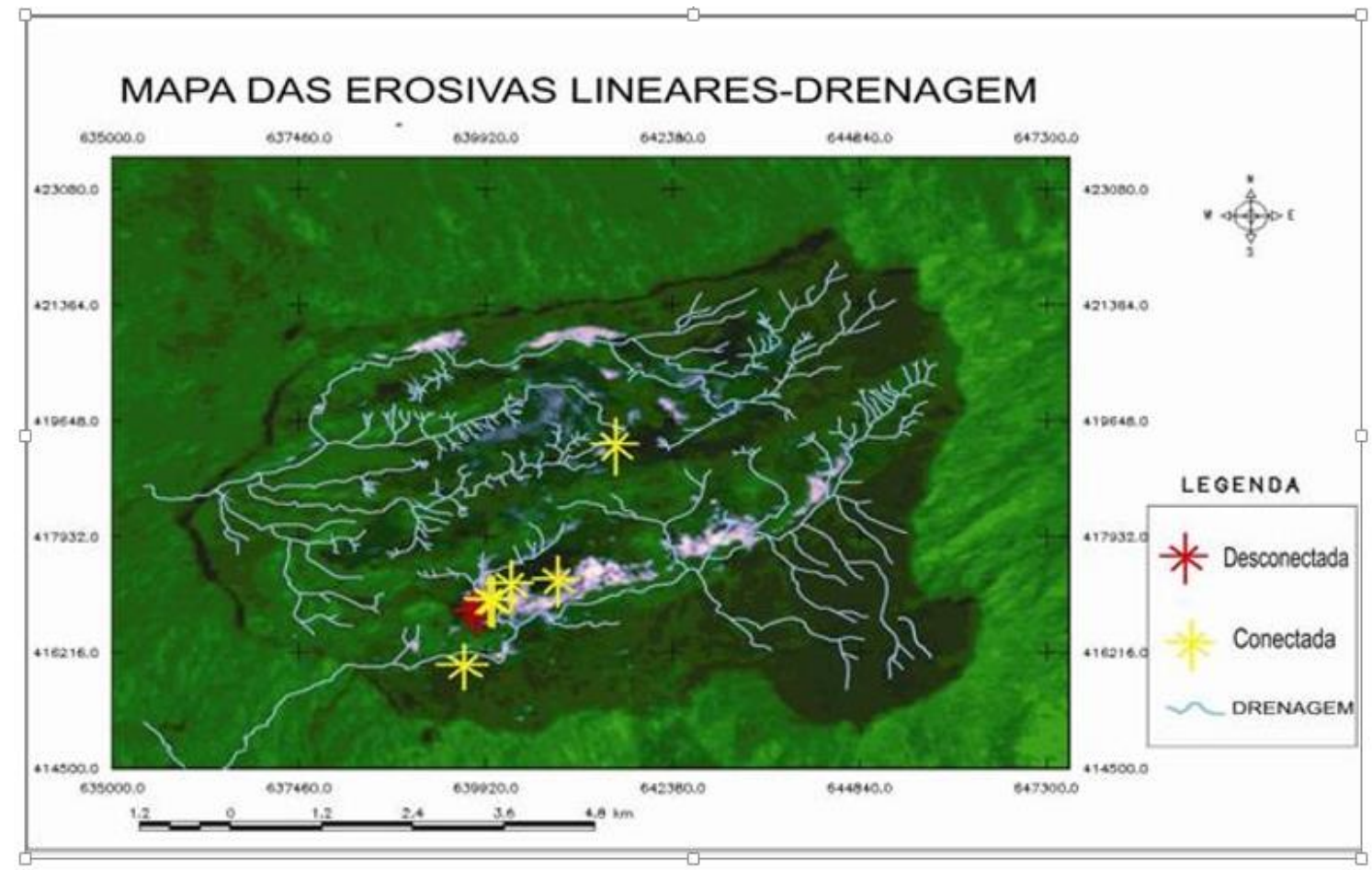

A cobertura vegetal nas feições erosivas foi analisada quanto a sua localização nos taludes e fundo do canal. As voçorocas apresentaram predominantemente, vegetação do tipo mista, que são as que contem vegetação recobrindo partes da erosão, correspondendo a 66,67\%. As voçorocas que não dispõe de vegetação em seus taludes e canal, as ativas, corresponderam $33,33 \%$.

\section{CONCLUSÃO}

A ação erosiva linear na serra do Tepequém promove mudanças significativas na paisagem. Canais em erosões de variadas profundidades encontram-se em áreas de planícies intermontanas, e secundariamente em encostas, que seguem o mesmo alinhamento de estruturas geológicas. 
Por meio da obtenção de dados morfométricos, foi possível conferir a dimensão da degradação do solo na serra Tepequém, constatado em observações e analises de campo, que elas aumentam a cada nova tomada de medição.

A evolução das feições erosivas reflete a combinação da fragilidade do solo, associada à ação antrópica. Um fator crucial no início erosão e a retirada da vegetação.

A falta de vegetação facilita a remoção dos sedimentos e intensifica a ação das aguas sobre os solos arenosos.

A partir da análise do cenário atual, foi possível concluir, que se não forem tomadas medidas mitigadoras, com o decorrer o tempo as erosões terão proporções progressivamente continuada.

A morfologia linear das voçorocas é condicionada por contatos litológicos e feições geológicas (falhas e fraturas) e as feições do tipo bifurcadas estão associadas aos processos de erosão superficial e subsuperficial (dutos biogênicos e áreas de abatimento por fluxo subsuperficial).

As drenagens apresentam controle estrutural por sua vez às voçorocas seguem esse mesmo controle, sendo do tipo conectada. Aonde ocorre a presença da cobertura vegetal o processo erosivo nos talude e vales e menos intenso.

Com base na análise das feições erosivas, a evolução e particular em cada voçoroca, mesmo naquelas que apresentaram algumas características similares, sendo necessário um acompanhamento e estudo mais prolongado para entender a dinâmica e a contribuição para a paisagem de entorno.

\section{REFERÊNCIAS}

BESERRA NETA L.C.; C.; COSTA, M. L.; BORGES, M. S. 2007. A Planície Intermontana Tepequém, Roraima, e sua vulnerabilidade erosiva. In: ROSA COSTA, L. t.; KLEIN, E. L.; VIGLIO, E. P. (Eds.) Contribuições a Geologia da Amazônia. Belém: SGB - Núcleo Norte, v. 5, p.89-100.

BIGARELLA, J. J; BECKER, R. D; SANTOS, G. F. dos. Estrutura e origem das paisagens tropicais e subtropicais. Florianópolis: UFSC. v II. 2007.

BORGES, F. R. e D’ANTONA, F. J. G. 1988. Geologia e Mineralizações da Serra do Tepequém-RR. In: Congresso Brasileiro de Geologia. 35., Belém, Anais..., v. 1. P. 155-163.

Cavalcante et al., $2019 \quad$ ISSN 0104-5490 270


BRASIL 1975. Projeto RADAMBRASIL folha NA-20 Boa Vista e parte das folhas NA-21 Tumucumaque, NB-20 Roraima e NB-21; geomorfologia, pedologia, vegetação e uso potencial da terra, Ministério de Minas e Energia/DNPM, Rio de Janeiro.

CARVALHO, D.F.; CRUZ, E.S.; PINTO, M.F.; SILVA, L.B.; GUERRA, J.G.M. Revista Brasileira de Engenharia Agrícola e Ambiental, Campina Grande, PB, UAEA/UFCG. v. 13, n. 1, p. 3-9, 2009.

COELHO NETTO, A.L. Hidrologia de encosta na interface com a geomorfologia. In. GUERRA, A.J.T.; CUNHA, S.B. Geomorfologia: uma atualização de bases e conceitos. Rio de Janeiro:Ed.Bertrand, 1994.

GUERRA, A. T. Estudo Geográfico do Território Federal de Roraima. Rio de Janeiro: IBGE, 1957. $252 \mathrm{p}$.

GUERRA, A. T.; Silva, A. S.; Botelho, R. G. M. Erosão e conservação dos solos: conceitos, temas e aplicações. Ed. Rio de Janeiro: Bertrand Brasil, 1999.

GUERRA, A. T. Anuário do Instituto de Geociências, UFRJ, 93-114 volume 20-in Ravinas processo de formação e desenvolvimento, v. 20 p.9-26, 2007.

GUERRA, A.J.T. O papel da matéria orgânica e dos agregados na erodibilidade dos solos. Anuário do Instituto de Geociências da UFRJ, 13, p.43-52. 1990.

GUERRA, A.T., e GUERRA, A.J.T. Novo Dicionário Geológico-Geomorfológico. Editora Bertrand Brasil, Rio de Janeiro. 2010.

MELO, E. C.; ALMEIDA FILHO, R. Mapeamento de Áreas Degradadas Pela Atividade de Garimpos na Região da Serra Tepequém (RR), Através de Imagens Landsat-TM. VIII Simpósio Brasileiro de Sensoriamento Remoto, Salvador, Brasil, 14-19 abril 1996, INPE, p. 639-645.

MOURA, D. V.; SIMÕES, C. S.A evolução histórica do conceito de paisagem. In: Ambiente e educação. vol. 15. 2010. 
TARDIN, R. Ordenação Sistêmica da Paisagem. In: I Enanparq. Rio de Janeiro, 2010.

TAVARES JUNIOR, S. S. 2004. Utilização de Imagens de Sensoriamento Remoto, Dados Aerogeofisicos e de técnicas de integração digital para o estudo geológico do Norte do estado de Roraima Brasil. Tese de Doutorado. INPE, 226p.

VOLK, L. B. S.; COGO, N. P.; STRECK, E. V. Erosão hídrica influenciada por condições físicas de superfície e subsuperfície do solo resultantes do seu manejo, na ausência de cobertura vegetal. Revista Brasileira de Ciências do Solo, Viçosa, v.28, n.4, p.585-596, 2004.

VIEIRA, A.; GONÇALVES, A. B.; LOURENÇO, L.; NUNES, A. (2012). Medidas de mitigação da erosão em canais: aplicação em áreas ardidas no NW de Portugal. Revista Geonorte, 1(4), 800-815. 